\title{
Improvement in Thixoforging of 7075 Aluminium Alloys at High Solid Fraction
}

\author{
G. Vaneetveld ${ }^{1, a}$, A. Rassili ${ }^{1, b}$, J.-C. Pierret ${ }^{1, c}$ and J. Lecomte-Beckers ${ }^{2, d}$ \\ ${ }^{1}$ ThixoUnit Ulg, PiMW B56, University of Liège, Sart Tilman, 4000 Liège, Belgium \\ ${ }^{2}$ MMS, B52, University of Liège, Sart Tilman, 4000 Liège, Belgium

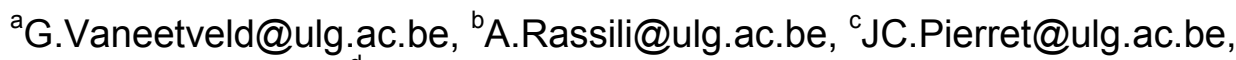 \\ dacqueline.Lecomte@ulg.ac.be
}

Keywords: thixoforging, 7075 alloys, hot tool, solid fraction, aluminium, semi-solid.

\begin{abstract}
Thixoforging is a type of semi-solid metal processing at high solid fraction $\left(0.5<\mathrm{f}_{\mathrm{s}}<1\right)$. 7075 aluminium alloys have been used as a feedstock for thixoforging in order to investigate thixoformability of a high performance aluminium alloy at high solid fraction. Higher solid fraction of 7075 alloy is less sensitive to temperature, avoids metal splash at high speed and allows laminar flow at high speed. Hot tool combined with lubricant tool coating are used to slow down the solidification rate of the high solid fraction metal by decreasing thermal exchanges with the tool. Improved thermal and forming parameters [1-2] will be applied to produce an automotive component by thixoforging and mechanical properties have been measured from tensile samples. High mechanical properties are obtained after T6 thermal treatment.
\end{abstract}

\section{Introduction}

Thixoforging process. Thixoforming process is a semisolid metal processing route (SSM), which involves forming of alloys in the semisolid state to near net shaped products [3]. For this to be possible, the microstructure of the semisolid must consist of globular solid grains surrounded by a liquid matrix. The mixture will then behave thixotropically: if it is sheared, the viscosity decreases and it flows like a liquid, but if allowed to stand, it thickens again. Thixoforging is a thixoforming process at high solid fraction where parts are shaped in one step and their mechanical properties can achieve values obtained by conventional forging with the advantage of the capacity to form parts with complex geometries [4].

Material. The required microstructure can be obtained by numerous routes. In the present work, alloy $7075(\mathrm{Al}-(5.1-6.1) \mathrm{Zn}-(2.1-2.9) \mathrm{Mg}-(1.2-2.0) \mathrm{Cu}-0.5 \mathrm{Fe}-0.4 \mathrm{Si}-(0.18-0.28) \mathrm{Cr}-0.3 \mathrm{Mn}-$ $0.2 \mathrm{Ti}$, all composition in wt-\% unless otherwise stated [5]) is studied. The 7075 aluminium alloy is a wrought alloy that shows, by DSC analysis, less sensitivity to temperature variation at high solid fraction (Fig. 1); this is why solid state route is investigated.

This solid route is the recrystallisation and partial melting (RAP) [6]. Firstly, the material is hot worked e.g. by extrusion. The extrusion has taken place below the recrystallisation temperature and the starting material for this work has long, thin grains, typical of an extruded microstructure. Secondly, on reheating into the semisolid state, recrystallisation takes place and the liquid penetrates the recrystallised boundaries so resulting in spheroids surrounded by liquid. There are two main advantages of this solid state route. Firstly, some alloys are supplied in the extruded state (i.e.

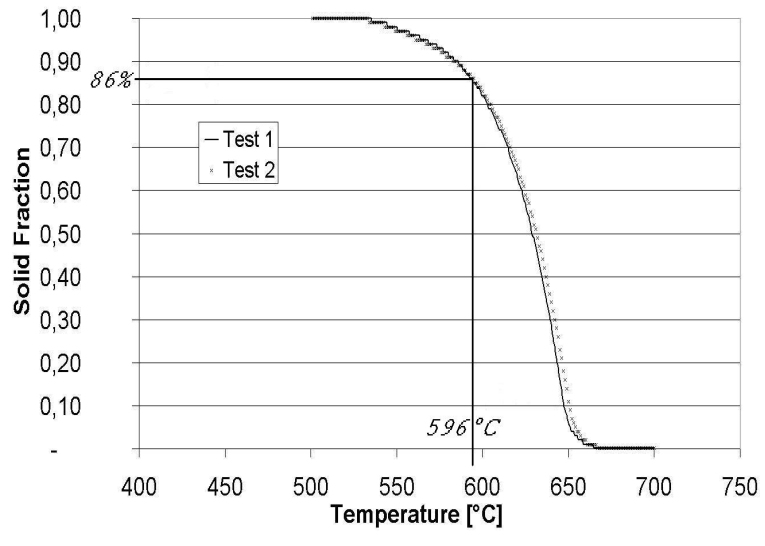

Fig. 1: Solid fraction vs. temperature obtained by DSC analysis at a heating rate of $15^{\circ} \mathrm{C} / \mathrm{min}$ 
worked) in any case. Secondly, the spheroids are

more fully rounded than those from, for example, the standard commercial route to spheroidal microstructures, like magnetohydrodynamic (MHD) stirring. The main disadvantages are that there may be variation in the amount of stored work across the section, resulting in inhomogeneity, and extrusion can be difficult and expensive with larger slug ${ }^{1}$ diameters [7].

\section{Experimental investigations}

Equipment. To perform the experiments, a $5000 \mathrm{kN}$ hydraulic press with punches at $1000 \mathrm{kN}$ is used. The press is driven to reach a position: the press will use the force needed to reach this position. The maximal punch speed during the shaping is $0.75 \mathrm{~m} / \mathrm{s}$. A $150 \mathrm{~kW}$ generator is used with a parabolic inductor, shown in figure 2 , to reach homogeneous temperature from the bottom to the top of the slug. Temperatures are measured in the middle of the slug at the centre and at the edge with $2 \mathrm{~mm}$ thermocouples K.

Material. Standard extruded 7075 aluminium alloy in T6 condition with an extrusion ratio ${ }^{2}$ of 1:16 is used. To obtain a high solid fraction with homogeneous round recrystallised grains, inductive heating is used to apply the RAP process to a slug placed on a ceramic cylinder $(\mathrm{d}=33 \mathrm{~mm}, \mathrm{~h}=30 \mathrm{~mm})$ at room temperature. A seven steps heating cycle at low frequency $(2.3 \mathrm{kHz})$ is used with 1 bar argon protective atmosphere to approach smoothly $600^{\circ} \mathrm{C}$ in order to allow the liquid fraction appears. Slugs of $30 \mathrm{~mm}$ diameter and $59 \mathrm{~mm}$ length, are machined from a rolled bar of $35 \mathrm{~mm}$ diameter to remove the layer that has difficulties to recrystallise during heating. These improved parameters [2] are used to shape SKL Flange parts redesigned for thixoforging process (Fig. 3).

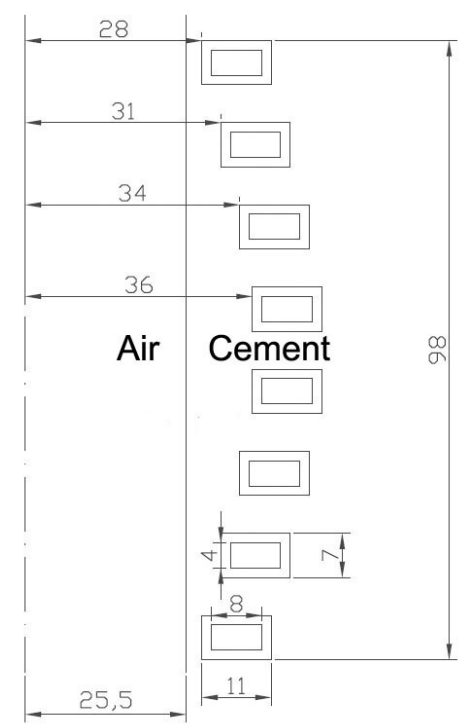

Fig. 2 : Parabolic inductor dimensions in [mm]

Transportation. At the end of the heating cycle, a 6 axes robot is used to bring the slug without protective atmosphere from the inductor above the closed tool [4]. The time of the transportation between the end of the heating cycle and the shaping is about 4 seconds.

Thixoforging process. The material used for the die is a tool steel (X38CrMoV5). Fast punch speed, tool temperatures $\left(24^{\circ} \mathrm{C}, 60^{\circ} \mathrm{C}\right.$ and $90^{\circ} \mathrm{C}$ ) and different tool lubricants coating (Ceraspray and Boron Nitride) are tested to decrease thermal exchanges between semisolid material and the tool [1, 4]. For a given tool temperature and punch speed, the forming load and the external quality of the part are observed by using different tool lubricants coating procedures:

- Boron Nitride;

- Ceraspray;

- Ceraspray + Boron Nitride;

- Boron Nitride + Ceraspray;

- No coating.

These experiments are done, gradually, with the same heating cycle of the slug.

\footnotetext{
${ }^{1}$ Small cylinder cut from extruded bar.

${ }^{2}$ The extrusion ratio is the ratio of the area of the initial slug to the area of the extruded product.
} 
Three parts shaped during identical conditions showing best compromise between low load and low thermal exchanges with tool are analyzed from microstructures and mechanical properties point of view. These parts are cut axially and etched with Keller's reagent for microstructure observation. After observation, the three half parts from each part are heat treated with $\mathrm{T}^{3}$. Two tensile specimens (NBN EN 10002-1:2002 norm) are machined from heat treated first half part and as-rought second half part: the first from the one without thermal treatment and the second one from the other thermal treated with $\mathrm{T}^{3}$ (Fig. 3).

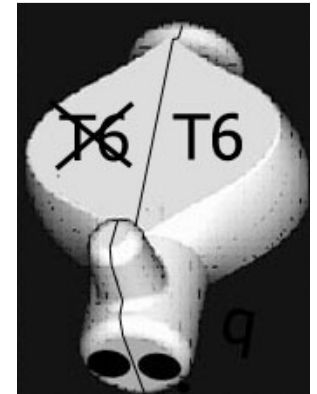

Fig. 3: Two tensile specimens machined in SKL Flange part

\section{Results and discussion}

Equipment. Maximal speed used with such tool is 0,315 $\mathrm{m} / \mathrm{s}$ according to figure 5 . To perform these experiments, a maximal pressure of $600 \mathrm{kN}$ was used. Different tool temperatures were used to observe influences on the load.

Material. Using the heating cycle shown below (Fig. 6 ), a homogeneous microstructure with round grains of about $150 \mu \mathrm{m}$ diameter is obtained from the transversal section of the slug (Fig. 4). Only few elongated unrecrystallized grains remain in the centre of the slug [2]. So the energy stored during extrusion was high enough (extruded ratio of $1: 16$ ) to recrystallise completely a slug of $35 \mathrm{~mm}$ diameter machined at $30 \mathrm{~mm}$.

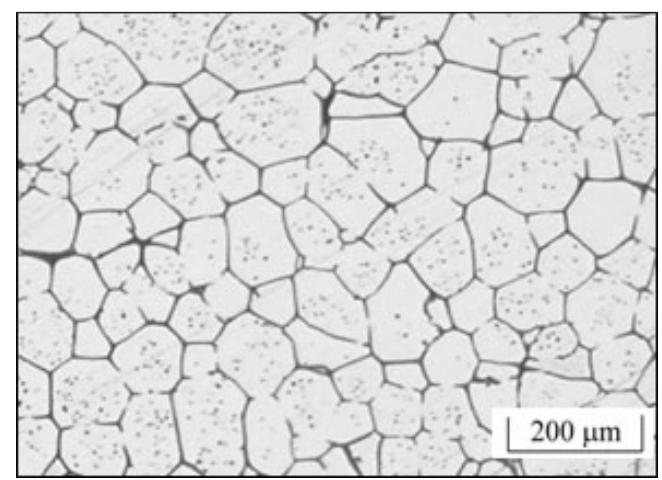

Fig. 4: Microstructure of recrystallised grains

The solid fraction, measured by line interceipt method excluding entrapped liquid, reaches 0.89 after water quenching, three seconds after the end of the heating cycle. The solid fraction graph (Fig. 1) shows that a temperature of $596^{\circ} \mathrm{C}$ corresponds to a solid fraction of 0.86 that is not far from the calculated solid fraction (0.89) from observed microstructures. The difference in solid fraction is because the microstructure is not cooled down fast enough to observe microstructure at $596^{\circ} \mathrm{C}$. A drawback of using high solid fraction is the high solidification rate that leads to the freezing flow ${ }^{4}$ during the thixoforging [4].

Transportation. As seen in figure 6, transportation time of 4 seconds leads to radial

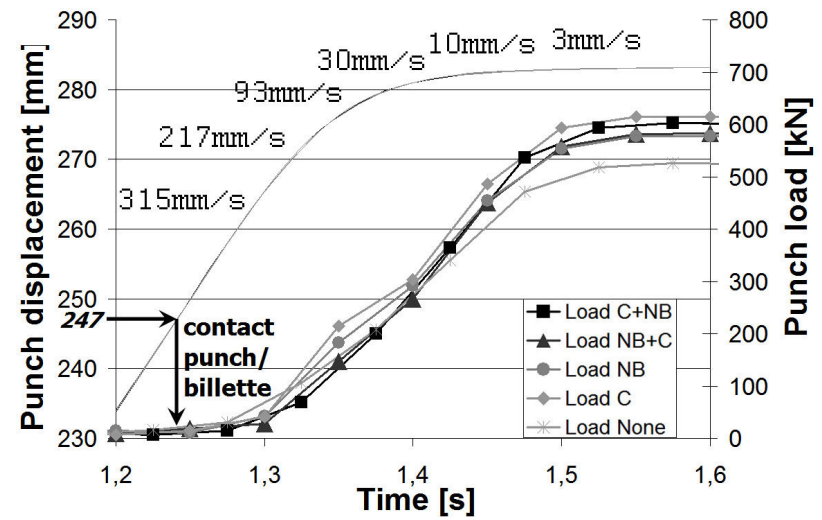

Fig. 5: Evolution of the load and displacement of the punch during thixoforging of a part in a tool at $60^{\circ} \mathrm{C}$ for different lubricants homogeneous temperature inside the slug with a maximal difference of $0.3^{\circ} \mathrm{C}$ between the side and the centre of the slug at the thixoforging.

Thixoforging process. The graph in figure 5 shows the load used to shape parts with different lubricants. Firstly a load of $15 \mathrm{kN}$ is used to compress freely the slug. Secondly, the load increases, to fully fill the tool as illustrated in figure 7 to reach the final position. The maximal pressure used to reach the final position is $600 \mathrm{kN}$.

Tool temperature influences the load. Higher tool temperature slightly decreases the load (about some tons). Most of experiments were done with tool at $60^{\circ} \mathrm{C}$ because it was the running temperature without heating tool.

\footnotetext{
${ }^{3} \mathrm{~T} 6: 475^{\circ} \mathrm{C}$ for $65 \mathrm{~min}$ - water quenched $-120^{\circ} \mathrm{C}$ for 24 hours.

${ }^{4}$ Solidification of the material flow due to thermal exchanges with the tool during tool filling.
} 


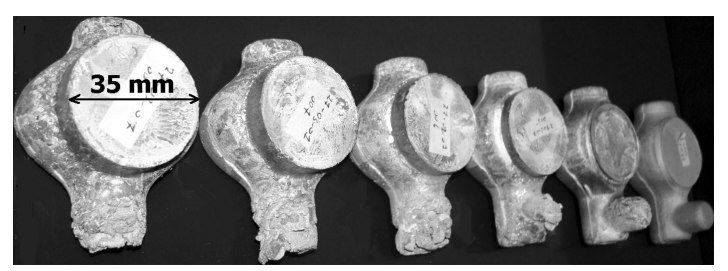

Fig. 7: Laminar flow evolution in the tool

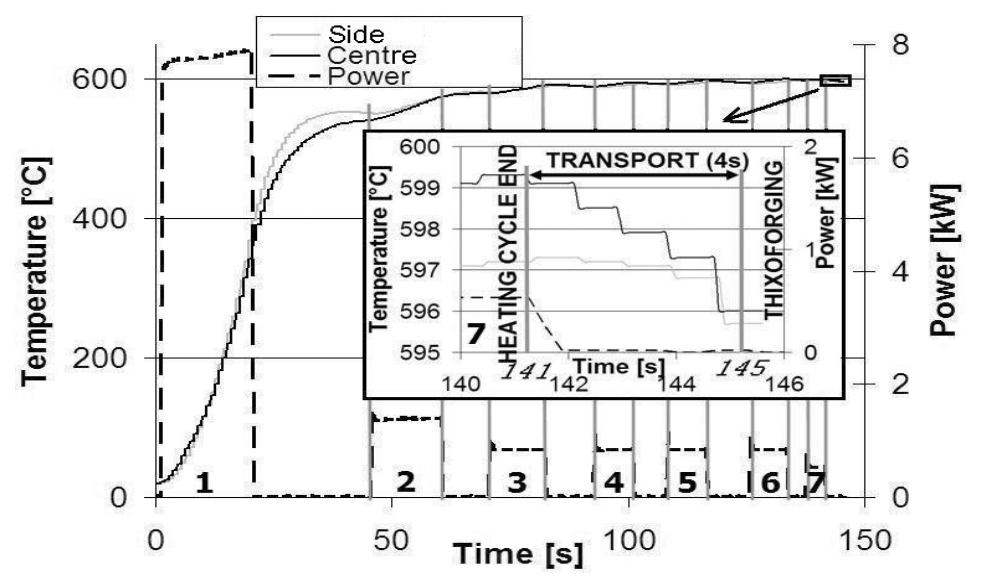

Fig. 6: Temperature evolution during and after heating cycle with corresponding generator powers

Lubricant tests. As shown in figure 5, from the higher load to the lower:

1. $615 \mathrm{kN}$ for Ceraspray tool coating.

2. $603 \mathrm{kN}$ for the Ceraspray layer in contact with the tool and Boron Nitride layer over it.

3. $583 \mathrm{kN}$ for the Boron Nitride tool coating.

4. $578 \mathrm{kN}$ for the Boron Nitride in contact with the tool and Ceraspray layer over it.

5. $526 \mathrm{kN}$ for the thixoforging without lubricant.

The friction force between lubricant and semisolid material can explain these results. The lubricants are applied as solid powder coating on tool. The main benefit of these lubricants is to help for part removing from the tool : so lubricants can better be called tool protectors. For the aluminium material, lubricant protects tool steel against chemical attack from aluminium. Parts thixoforged with Ceraspray coating show better external quality than others because of the lower thermal exchanges with the tool that reduces the freezing flow. The best compromise between low tool wear, low load, low thermal exchanges is to combine benefits of Boron Nitride and Ceraspray: Boron Nitride in contact with the tool to limit friction forces during tool filling and Ceraspray layer over it to decrease thermal exchanges. Three parts thixoforged with this coating are analysed below. Too much lubricant damages the surface of the part because the lubricant is solid.

Microstructure. Figure 8a shows us that higher pressure deforms plastically a grains zone near the punch instead of reducing porosity of the part. This means that the material around the punch is already solid before the end of the thixoforging. So increase the pressure at the end of the thixoforging is not enough to improve the quality of the part: the freezing flow has to be reduced.

Non-recrystallized grains, shown in figure $8 \mathrm{~b}$, are deformed and don't create defect in the microstructure. Because of their thickness of about $100 \mu \mathrm{m}$, most of them are plastically deformed or broken by the flow. They don't make significant resistance to the flow.

Lower cracks are observed compared to the previous paper [4] as shown in figure 8c due to the fast cooling in the tool during the thixoforging. To reduce these cracks, tool should be heated to a

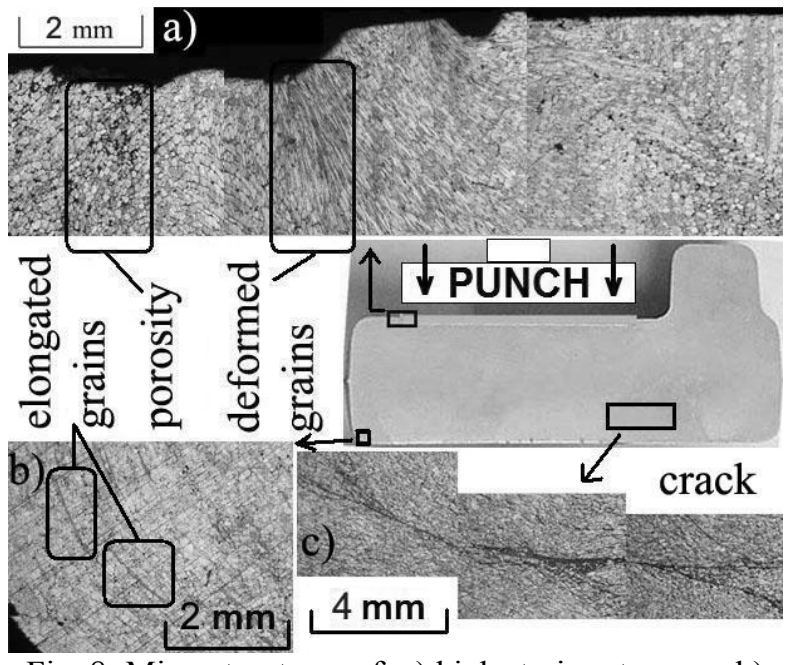

Fig. 8: Microstructures of: a) high strain rate zone; b) elongated grains not broken; c) crack higher temperature. But at higher temperature, punch speed needs to be adapted. If the temperature is high enough, punch speed can be reduced to avoid cracks due to the material flow behaviour [1]. 
In a early paper [4], macrosegregation solid/liquid was observed on parts shaped with cold tool due to the freezing flow. In these experiments, we couldn't observe these macrosegregations probably due to the heated tool that delays the freezing flow. It may be assumed that the freezing flow starts from the nose of the part to end at the slug location. The longer is the solidification delay, the better is the pressure distribution in the part during forming, the better is the quality of the part.

Mechanical properties. Two tensile specimens from each part are tested. One is machined from the half part without thermal treatment and the other from the second part with thermal treatment. Results are shown in the table 1.

After T6 thermal treatement, an increase of $63 \%$ for the $\mathrm{Rp} 0,2$ and about $75 \%$ for the Rm due to defects reducing and precipitation hardening are observed. If these results are compared with rolled bar in T6 condition, they are $28 \%$ lower for $\mathrm{Rp} 0,2,23 \%$ lower for $\mathrm{Rm}$ and $28 \%$ lower for elongation.

\begin{tabular}{|l|l|l|l|}
\hline & $\begin{array}{l}\text { Rm } \\
{[\mathrm{MPa}]}\end{array}$ & $\begin{array}{l}\text { Rp0,2 } \\
{[\mathrm{MPa}]}\end{array}$ & $\begin{array}{l}\text { A } \\
{[\%]}\end{array}$ \\
\hline Feedstk(rolled)@T6 & 658 & 609 & 9.7 \\
\hline Part 2@T6 & 533 & 478 & $4.1 *$ \\
\hline Part 3@T6 & 533 & 473 & 7.6 \\
\hline Part 1 & 294 & 289 & 0.3 \\
\hline Part 2 & 351 & 295 & 1.8 \\
\hline Part 3 & 306 & 293 & 0.4 \\
\hline
\end{tabular}

Table 1: Mechanical properties of 7075 asthixoformed and in T6 condition. $(*)$ break occured outside the extensiometer

\section{Conclusion}

The goal of this paper is to apply improved parameters [1-2] in thixoforging wrought aluminium alloy 7075 industrial parts and to observe their quality and their mechanical properties.

The RAP process was used with a seven step heating cycles of 141 seconds to obtain recrystallisation and to enhance small globular grains $(\approx 150 \mu \mathrm{m})$ surrounded by a liquid matrix. With an extrusion ratio of 1:16, a homogeneous recrystallisation is obtained for a slug of $35 \mathrm{~mm}$ diameter machined to $30 \mathrm{~mm}$. A high solid fraction of 0.89 is used. A drawback of this high solid fraction is the high solidification rate that can be limited by reducing thermal exchanges between part and the tool: parts are thixoforged in warm tool, at high speed with high load to reduce defects like macrosegregation solid/liquid [4]. The longer is the solidification delay during thixoforging, the better is the pressure distribution in the part during forming, the better is the quality of the part.

Despite these optimized parameters, few cracks remains due to the cooling in the tool after thixoforging. A solution is to increase the temperature of the tool to slow down the cooling of parts. By increasing temperature, punch speed has to be adapted to avoid defects due to the material flow behaviour [1].

Different lubricants are tested. The best compromise between low tool wear, low thermal exchanges and low load, is to apply Boron Nitride coating on the tool to reduce load and a Ceraspray layer over it to reduce thermal exchanges between the material and the tool to improve quality of the part.

The difference in temperatures between the centre and the edge of the slug decreases during the short transportation between inductor and tool to reach $0,3^{\circ} \mathrm{C}$ after 4 seconds.

High mechanical properties are reached by using optimized parameters. To increase quality of thixoforged parts, temperature of the tool should be higher with adapted punch speed to reduce cracking due to fast cooling.

\section{Aknowledgement}

The authors gratefully acknowledge University of Liège and Walloon Region (First Europe Project) for their support. 


\section{References}

[1] G. Vaneetveld, A. Rassili, J-C. Pierret, J. Lecomte-Beckers; Extrusion test of 7075 aluminium alloys at high solid fraction; Int J Mater Form; DOI 10.1007/s12289-008-0220-z.

[2] G. Vaneetveld, A. Rassili, H. V. Atkinson; Influence of parameters during induction heating cycle of 7075 aluminium alloy with RAP process; submitted to S2P Conference 2008.

[3] M. C. Flemings: Metall. Trans. A, 1991, 22A, 957-981.

[4] G. Vaneetveld, A. Rassili, J. Lecomte-Beckers, H.V. Atkinson; Thixoforging of 7075 aluminium alloys at high solid fraction; Trans. Tech Publications, Solid State Phenomena Vols. 116-117, pp. 762-765, Switzerland, 2006.

[5] Metals Handbook ${ }^{\circledR}$, Desk Ed., ASM, Ohio, 1984.

[6] D.H. Kirkwood, C.M. Sellars, L.G. Elias-Boyed. Thixotropic materials. European Patent No. 0305375 B1; 28 October 1992.

[7] K. Burke, G. Vaneetveld, H.V. Atkinson; Recrystallization in the semi-solid state in 7075 Aluminium Alloy, for publication in Material Sciences and Engineering. 
Semi-Solid Processing of Alloys and Composites X

doi:10.4028/www.scientific.net/SSP.141-143

Improvement in Thixoforging of $\mathbf{7 0 7 5}$ Aluminium Alloys at High Solid Fraction doi:10.4028/www.scientific.net/SSP.141-143.707 